CASE REPORTS

\title{
Syncope in myxoedema due to transient ventricular fibrillation
}

\author{
Michael B. Macaulay \\ M.A., D.M., M.R.C.P. \\ Senior Medical Registrar
}

\author{
ROBERT J. SHEPHERD \\ M.B., Ch.B. \\ Senior House Officer in Medicine
}

Regional Cardiac Centre, Sefton General Hospital, Smithdown Road, Liverpool, L15 2HE

\section{Introduction}

Attacks of syncope or epilepsy are well recognized hazards of untreated myxoedema (Jellınek, 1962; Sanders, 1962; Menon, 1967) and commonly cease once treatment has started. Such episodes are rarely witnessed by doctors or trained ancillary staff, but have been assumed to arise from cerebral dysfunction, since abnormal electroencephalogram (EEG) patterns are commonly found in this disease. Jellinek however comments on the lack of correlation between the occurrence of attacks of unconsciousness and the severity of EEG changes.

A patient with severe myxoedema who was recently under our care had a 3-year history of syncopal attacks, one of which fortuitously occurred during the recording of an electrocardiogram (ECG). The episode was shown to be Stokes-Adams syncope associated with transient ventricular fibrillation. The case is described here.

\section{Case report}

A 66-year-old retired engine driver was admitted with acute urinary retention of $20 \mathrm{hr}$ duration. The presence of bradycardia led the admitting house surgeon to order an ECG.

The patient had been prone to winter bronchitis for many years. Progressive slowing of mental and physical activities had been present for 5 years and he had suffered mild angina pectoris. He had lost interest in all affairs and had suffered a personality change so that he had become unpredictably badtempered and awkward. His wife described him as 'not the man I married'. For 2 years he had complained increasingly of the cold, his face had become puffy and his voice gruff. He had been treated with frusemide, digoxin and slow $\mathrm{K}$ since an episode of congestive cardiac failure 4 months before admission.

The first syncopal attack had occurred 3 years previously. Recurrent episodes were initially separated by many months, but their frequency increased steadily and in the week before admission there had been six attacks. Loss of consciousness occurred suddenly and unpredictably with the patient falling to the floor. Sometimes he would be unconscious only a few seconds, during which he would lie motionless, on other occasions he remained unconscious for 2 or 3 min and these longer attacks were always accompanied by convulsions.

On examination he presented the characteristic appearance of myxoedema. He was lethargic and deaf and had a gruff voice. His skin and hair were coarse and dry, there was periorbital puffiness and there was marked delay in the relaxation phase of his tendon reflexes. His pulse was irregular at $42 / \mathrm{min}$, there was considerable cardiac enlargement and his blood pressure was 170/60. He had a distended bladder and rectal examination revealed an enlarged prostate. Chest X-ray confirmed the cardiac enlargement. Plasma urea was $51 \mathrm{mg} / 100 \mathrm{ml}$, sodium 137 $\mathrm{mEq} / \mathrm{l}$, potassium $3.2 \mathrm{mEq} / 1$, chloride $93 \mathrm{mEq} / \mathrm{l}$ and $\mathrm{CO}_{2} 31.5 \mathrm{mEq} / \mathrm{l}$. An initial protein-bound iodine estimation was technically unsatisfactory, so after 2 months treatment with L-thyroxine ${ }^{132} \mathrm{I}$ uptake was estimated before and after stimulation with thyroid stimulating hormone (TSH). This was low at $9.3 \%$ and showed no significant rise after TSH had been given.

ECG showed sinus rhythm with a prolonged PR interval $(0.24 \mathrm{sec})$ and left bundle branch block (LBBB). Multifocal ventricular ectopic beats were so frequent that the basic sinus rate was impossible to assess. During the recording of V4 the patient suddenly developed ventricular fibrillation (Fig. 1). This occurred almost continuously for a minute, interspersed with one or two sinus beats, until it spontaneously reverted to sinus rhythm. The patient lost consciousness but did not convulse and afterwards said he had had a typical 'blackout'.

A bipolar pacing catheter was inserted the same day into his right ventricle by a percutaneous supraclavicular approach (Macaulay \& Wright, 1970) and the patient was paced on demand at a rate of $80 / \mathrm{min}$. 

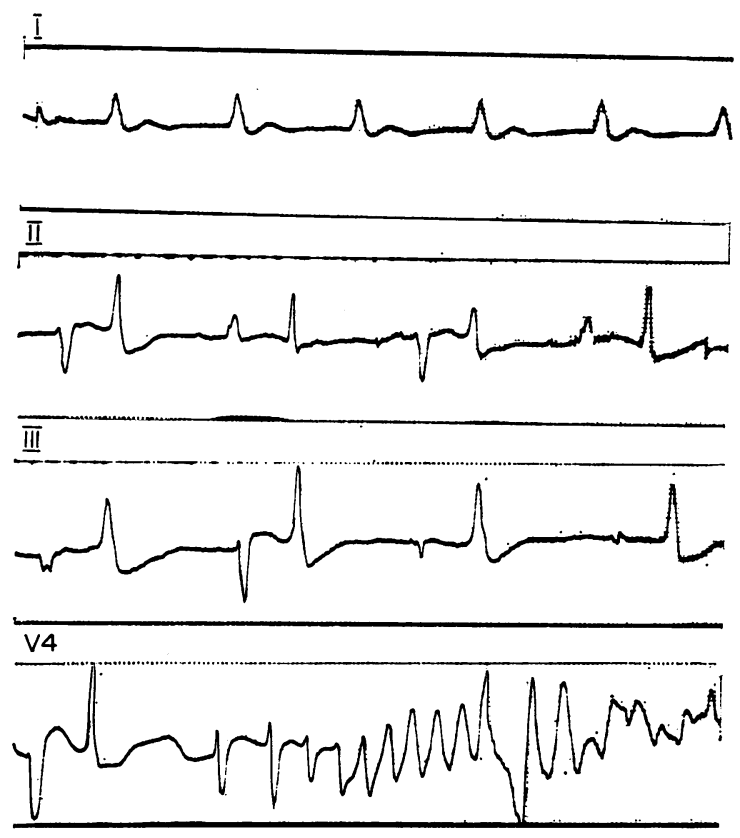

FIG. 1. ECG showing multiple ectopic beats and left bundle branch block (LBBB). Lead V4 records the onset of ventricular fibrillation.

Ventricular ectopic activity immediately ceased and did not recur. Treatment with L-thyroxine was started at an initial dose of $0.05 \mathrm{mg}$ daily, increasing after 1 week to $0.1 \mathrm{mg}$ daily and after 3 weeks to $0.2 \mathrm{mg}$ daily.

Within 10 days he had spontaneous sinus rhythm at a rate of $80 / \mathrm{min}$ and pacing was discontinued. No further ventricular arrhythmia or syncope occurred. Over the next 7 weeks there was dramatic improvement in his mental and physical state. His wife found him better than he had been for 10 years and commented 'You have given my husband back to me!' Seven weeks from his initial admission prostatectomy was performed and the patient was discharged 2 weeks later. Up to the present he has remained well and has had no further syncope. His ECG shows sinus rhythm without ventricular ectopics, but the $P R$ interval remains prolonged at 0.24 sec and LBBB persists.

\section{Discussion}

The diagnosis of myxoedema seems certain here, and the syncopal episodes, cured by treatment with L-thyroxine, were similar to those described previously in this disease. It is reasonable to presume that his previous syncopal episodes were also StokesAdams attacks, but without a chance ECG recording their arrhythmic nature would probably have been missed. Emergency cardiac pacing was under- taken in the belief that the episode of ventricula fibrillation had been associated with bradycardia anc an irritable ventricle. The immediate cessation of ventricular ectopic beats with pacing at a rate of: $80 / \mathrm{min}$, and the subsequent prevention of any furtheres syncopal attacks, confirms this view. This situationo is analogous to that found immediately after acuteo myocardial infarction where any form of bradycardiax, predisposes to serious ventricular arrhythmia (Adgey et al., 1968).

The relative parts played by coronary artery disease and metabolic disorder in myxoedema hearto disease remain debatable (Aber \& Thompson, $1964 ; \overrightarrow{\vec{\omega}}$ Cohen \& Lloyd-Thomas, 1966; Vanhaelst et al. 1967). Whatever the aetiology Vanhaelst et alo showed conduction defects to be three times 3 commoner in a myxoedematous as compared with ai control population. Isolated case reports haver appeared previously of myxoedematous patients 5 with ventricular tachycardia (Hansen, 1961; Wina- $\dot{\omega}$ wer, Rosen \& Cohn, 1963), Stokes-Adams attacks and complete heart block responding to thyroxine? (Lee \& Lewis, 1962) and spontaneous termination of ventricular fibrillation (Marcuson, 1965). It therefores seems likely that this case is not unique, but that syncopal attacks in myxoedema are due to cardiac $\vec{c}$ arrhythmias more commonly than has previous $1 y$ been realised.

\section{Acknowledgments}

This patient was admitted under the care of Mr R. M.O Jameson F.R.C.s. We are grateful to him for allowing us to음 publish details of the case. We are also grateful to Dr T.M.D.@ Gimlette M.R.C.P. for performing and interpreting the radio- $\overrightarrow{\vec{F}}$ iodine studies.

\section{References}

Aber, C.P. \& Thompson, G.S. (1964) The heart in hypothyroidism. American Heart Journal, 68, 428.

Adgey, A.A.J., Geddes, J.S., Mulholland, H.C., Keegan, D.A.J. \& PANTRIDGE, J.F. (1968) Incidence, significance and management of early bradyarrhythmia complicating acute myocardial infarction. Lancet, ii, 1097.

Cohen, R.D. \& Lloyd-Thomas, H.G. (1966) Exercise electrocardiogram in myxoedema. British Medical Journal, $\supset$ $2,327$.

HANSEN, J.E. (1961) Paroxysmal ventricular tachycardia associated with myxoedema. American Heart Journal, 61, N 692.

JELlineK, E.H. (1962) Fits, faints, coma and dementia in $\mathrm{N}$ myxoedema. Lancet, ii, 1010.

LEE, J.K. \& LEWIS, J.A. (1962) Myxoedema with complete A-V block and Adams-Stokes disease abolished with thyroid medication. British Heart Journal, 24, 253.

MaCAUlaY, M.B. \& WRIGHT, J.S. (1970) Transvenous cardiac $\mathbb{E}$ pacing. British Medical Journal, 4, 207.

MARCUSON, R.W. (1965) Ventricular fibrillation in myxoedema heart disease with spontaneous reversion. British Heart Journal, 27, 455. 
MenoN, I.S. (1967) Syncopal attacks in hypothyroid state. Journal of the Indian Medical Association, 48, 126.

SANDERS, V. (1962) Neurological manifestations of myxoedema. New England Journal of Medicine, 266, 599.

Vanhaelst, L., Neve, P., Chailly, P. \& Bastenie, P.A.
(1967) Coronary artery disease in hypothyroidism. Lancet. ii, 800 .

Winawer, S.J., Rosen, S.M. \& CoHn, H. (1963) Myxoedema coma with ventricular tachycardia. Archives of Internal Medicine, 111, 647.

\section{Fibrosing alveolitis and active chronic hepatitis without hyperglobulinaemia}

\author{
R. B. HudDY \\ B.M., M.R.C.P.
}

\author{
A. Ahmed \\ M.B., Ch.B.
}

\section{Manchester Royal Infirmary, Manchester, 13}

CASES of fibrosing alveolitis and active chronic hepatitis are rare. The small series reported by Turner-Warwick (1968) all had raised globulins, the range being from $4.0 \mathrm{~g} / 100 \mathrm{ml}$ to $5.8 \mathrm{~g} / 100 \mathrm{ml}$. We report a case in which the diagnosis was made in life and confirmed at necropsy, in whom the serum globulin level remained persistently normal.

\section{Case report}

The patient was a 61-year-old woman who presented in 1965 with a short history of cough and dyspnoea. Her chest X-ray at that time showed fairly widespread diffuse shadowing which was thought at first to be inflammatory, but showed little resolution after courses of treatment with penicillin and tetracycline. Tuberculosis was excluded by repeated sputum cultures. A diagnosis of idiopathic pulmonary fibrosis was made, and she was followed up for a time, but her symptoms did not progress. In 1968 she presented with a single, enlarged supraclavicular lymph node. This was excised and the histological appearance showed caseating granulomata. However, no acid-fast bacilli were seen on the sections. Nevertheless, she received 12-months' treatment with anti-tuberculous therapy. At the end of this time she was referred for review and further investigations of her chest condition, mainly because of the abnormal chest X-ray, though this had changed little over the years. She was fully investigated in July 1969.

Clinical examination revealed clubbing of the fingers, crepitations at the lung bases and a liver enlarged three fingers. Chest X-ray appearances, spirometry, $\mathrm{PaO}_{2}$ estimations at rest and after exercise and estimation of transfer factor (Table 1) all pointed clearly to a diagnosis of fibrosing alveolitis, but lung biopsy was not considered justifiable. The finding of hepatic enlargement did not at first suggest lupoid hepatitis; there was no history of jaundice, serum bilirubin was normal, spider naevi were not present and there was no splenomegaly. Liver function tests gave normal results for albumin and globulin, with normal electrophoretic strip and immune globulins, the level for the latter being as follows: IgG, $1300 \mathrm{mg} / 100 \mathrm{ml} ; \mathrm{IgA}, 170 \mathrm{mg} / 100 \mathrm{ml}$; IgM, $100 \mathrm{mg} / 100 \mathrm{ml}$. Serum transaminases and alkaline phosphatase were raised (44 KA Units $/ 100 \mathrm{ml}$ ) and 5-nucleotidase was grossly raised (148 Units). Tests for the LE phenomenon were positive, antinuclear factor was positive, smooth-muscle antibodies were positive at a titre of one in four, but thyroid antibodies, mitochondrial antibodies, tests for rheumatoid factor and Australia antigen were negative. Liver biopsy was carried out, and showed the characteristic appearances of active chronic hepatitis.

Treatment. In August 1969 treatment was started with prednisolone in a dose of $60 \mathrm{mg}$ daily, reducing over the course of the next 4 weeks to $20 \mathrm{mg}$ daily and maintaining this dose thereafter. There was some subjective improvement, though lung function tests did not change, and the ESR, which had previously been moderately raised, fell to normal, alka-

TABLE 1.

\begin{tabular}{lllc}
\hline & \multicolumn{1}{c}{ Initial values } & $\begin{array}{c}\text { After treatment } \\
\text { with steroids }\end{array}$ & $\begin{array}{c}\text { After treatment } \\
\text { with azathioprine }\end{array}$ \\
\hline Vital capacity & $1.31 / \mathrm{min}$ & $1.57 \mathrm{l} / \mathrm{min}$ & $1.55 \mathrm{l} / \mathrm{min}$ \\
FEV $_{1}$ & Normal & Normal & Normal \\
Transfer factor & $5.0 \mathrm{ml} \mathrm{CO} / \mathrm{min} / \mathrm{mmHg}$ & Unchanged & Unchanged \\
\hline
\end{tabular}

